\title{
Exercise training improves relaxation response and SOD-I expression in aortic and mesenteric rings from high caloric diet-fed rats
}

\author{
Camila de Moraes ${ }^{1}$, Ana Paula Couto Davel ${ }^{2}$, Luciana Venturini Rossoni², \\ Edson Antunes ${ }^{3}$ and Angelina Zanesco*4
}

\begin{abstract}
Address: ${ }^{1}$ Biological Science and Health, Faculty of Physical Education, Cruzeiro do Sul University, São Paulo (SP), Brazil, ${ }^{2}$ Department of Physiology and Biophysics, Institute of Biomedical Sciences (ICB-I), University of São Paulo, São Paulo (SP), Brazil, ${ }^{3}$ Department of Pharmacology, Faculty of Medical Sciences, University of Campinas, Campinas (SP), Brazil and ${ }^{4}$ Department of Physical Education; Institute of Bioscience, University of Sao Paulo State, Rio Claro (SP), Brazil

Email: Camila de Moraes - camila.moraes@unicsul.br; Ana Paula Couto Davel - anadavel@icb.usp.br;

Luciana Venturini Rossoni - Irossoni@icb.usp.br; Edson Antunes - edson.antunes@uol.com.br; Angelina Zanesco* - azanesco@rc.unesp.br

* Corresponding author
\end{abstract}

Published: 29 May 2008

BMC Physiology 2008, 8:12 doi:10.1186/1472-6793-8-12

This article is available from: http://www.biomedcentral.com/l472-6793/8//2

(c) 2008 de Moraes et al; licensee BioMed Central Ltd.

This is an Open Access article distributed under the terms of the Creative Commons Attribution License (http://creativecommons.org/licenses/by/2.0), which permits unrestricted use, distribution, and reproduction in any medium, provided the original work is properly cited.

\begin{abstract}
Background: Obesity has been associated with a variety of disease such as type II diabetes mellitus, arterial hypertension and atherosclerosis. Evidences have shown that exercise training promotes beneficial effects on these disorders, but the underlying mechanisms are not fully understood. The aim of this study was to investigate whether physical preconditioning prevents the deleterious effect of high caloric diet in vascular reactivity of rat aortic and mesenteric rings.
\end{abstract}

Methods: Male Wistar rats were divided into sedentary (SD); trained (TR); sedentary diet (SDD) and trained diet (TRD) groups. Run training (RT) was performed in sessions of 60 min, 5 days/week for 12 weeks $(70-80 \%$ $\left.\mathrm{VO}_{2 \max }\right)$. Triglycerides, glucose, insulin and nitrite/nitrate concentrations $\left(\mathrm{NO}_{\mathrm{x}}{ }^{-}\right)$were measured. Concentrationresponse curves to acetylcholine (ACh) and sodium nitroprusside (SNP) were obtained. Expression of $\mathrm{Cu} / \mathrm{Zn}$ superoxide dismutase (SOD-I) was assessed by Western blotting.

Results: High caloric diet increased triglycerides concentration (SDD: $216 \pm 25 \mathrm{mg} / \mathrm{dl}$ ) and exercise training restored to the baseline value (TRD: $89 \pm 9 \mathrm{mg} / \mathrm{dl}$ ). Physical preconditioning significantly reduced insulin levels in both groups (TR: $0.54 \pm 0.1$ and TRD: $1.24 \pm 0.3 \mathrm{ng} / \mathrm{ml}$ ) as compared to sedentary animals (SD: $0.87 \pm 0.1$ and SDD: $2.57 \pm 0.3 \mathrm{ng} / \mathrm{ml}$ ). On the other hand, glucose concentration was slightly increased by high caloric diet, and RT did not modify this parameter (SD: I $26 \pm 6$; TR: $140 \pm 8$; SDD: $156 \pm 8$ and TRD $153 \pm 9 \mathrm{mg} / \mathrm{dl}$ ). Neither high caloric diet nor RT modified NO- levels (SD: $27 \pm 4$; TR: $28 \pm 6$; SDD: $27 \pm 3$ and TRD: $30 \pm 2 \mu \mathrm{M}$ ). Functional assays showed that high caloric diet impaired the relaxing response to $A C h$ in mesenteric (about I3\%), but not in aortic rings. RT improved the relaxing responses to ACh either in aortic ( $28 \%$, for TR and $16 \%$, to TRD groups) or mesenteric rings (10\%, for TR and I7\%, to TRD groups) that was accompanied by up-regulation of SOD-I expression and reduction in triglycerides levels.

Conclusion: The improvement in endothelial function by physical preconditioning in mesenteric and aortic arteries from high caloric fed-rats was directly related to an increase in NO bioavailability to the smooth muscle mostly due to SOD-I up regulation. 


\section{Background}

Obesity is a public health problem and it is a major risk factor for a variety of diseases including arterial hypertension, diabetes mellitus, atherosclerosis and dyslipidemia [1]. Particularly, atherosclerosis is a chronic inflammatory disease associated with endothelium dysfunction and vascular smooth muscle growth resulting in imbalance of vasodilator and vasoconstrictor production by endothelial cells and decrease in vessel lumen [2]. It has been pointed out that oxidative stress associated with alterations in plasma lipid concentration are the main causes of atherosclerosis and both factors play a key role in this cardio-inflammatory disease [3-5].

Evidences have shown that high fat diet provokes alterations in lipid profile and endothelium dysfunction leading to impairment of vascular relaxing responses in rats and pigs [6-9]. A number of studies have reported that the beneficial effect of physical training in lowering LDL-cholesterol and increasing HDL-cholesterol particles [10], as well as improving the endothelium-derived relaxing response and lead to a prevention of atherosclerosis due to increased nitric oxide (NO) production and/or its bioavailability [11-18]. However, no studies exist investigating the effect of run training associated with high caloric diet in the vascular responsiveness in rats.

Therefore, the aim of the present study was to test the hypothesis that prior physical training promotes beneficial effects in the relaxing response of aortic and mesenteric rings from animals fed with high caloric diet and the underlying mechanism mediating this phenomenon. We also evaluated whether run training attenuates the endocrine-metabolic alterations produced by high caloric diet fed-rats.

\section{Methods}

\section{Animals and experimental protocol}

The animal protocols were approved by the Ethics Committee for Experimental Research of the State University of Campinas (UNICAMP). Male Wistar rats (10 weeks-old) were obtained from the Animal Care Facility of UNICAMP. Animals were maintained on a $12 \mathrm{~h}$ light/dark cycle, housed in groups of four animals and had free access to water and high caloric diet (56\% of carbohydrate, $18 \%$ of protein and $26 \%$ fat) or standard rat chow ( $40 \%$ carbohydrate, $26.5 \%$ protein and $3.8 \%$ as fat; Purina Co., Campinas-São Paulo, Brazil). Animals were divided into 4 groups: sedentary control (SD), trained control (TR), sedentary diet (SDD) and trained diet (TRD).

Experimental protocol consisted of 4 weeks of run training program prior to high caloric diet consumption, after which high caloric diet and exercise training were carried out simultaneously for further 8 weeks. Animals were trained in a treadmill with an intensity of $70-80 \%$ of maximal oxygen consumption, in sessions of 60 minutes, 5 days a week. Only the animals adapted to the treadmill were used in trained groups. The scheme below illustrates the experimental protocol design, (see Additional File 1).

\section{Concentration-response curves}

Aorta and superior mesenteric arteries were removed carefully and placed in freshly prepared Krebs solution containing (mM): $\mathrm{NaCl}, 118 ; \mathrm{NaHCO}_{3}$, 25; glucose, 5.6; KCl, 4.7; $\mathrm{KH}_{2} \mathrm{PO}_{4}, 1.2 ; \mathrm{MgSO}_{4}, 1.17$ and $\mathrm{CaCl}_{2}$, 2.5. The arteries were cleaned of all adherent tissue and cut into rings of approximately $2 \mathrm{~mm}$. Each ring was suspended between two wire hooks and mounted in $10 \mathrm{ml}$ organ chambers with Krebs solution at $37^{\circ} \mathrm{C}, \mathrm{pH} 7.4$, and continuously aerated with a mixture of $95 \% \mathrm{O}_{2}$ and $5 \% \mathrm{CO}_{2}$ under a resting tension of $10 \mathrm{mN}$. The tissues isometric tension was recorded by a force-displacement transducer (UgoBasile, Varese, Italy) connected to a PowerLab $400^{\mathrm{TM}}$ data acquisition system (ADInstruments Pty Ltd, Castle Hill, Australia).

After $1 \mathrm{~h}$ of stabilization period, intact endothelium aortic and mesenteric rings were pre-contracted with phenylephrine $(1 \mu \mathrm{M})$. Cumulative concentration-response curves to acetylcholine (ACh, $10 \mathrm{nM}-100 \mu \mathrm{M}$ ) and sodium nitroprusside (SNP, $100 \mathrm{pM}-100 \mathrm{nM}$ ) were obtained in aortic and mesenteric rings with intact endothelium. Concentration-response data were evaluated for a fit to a logistics function in the form:

$$
\mathrm{E}=\mathrm{E}_{\max } /\left(\left(1+\left(10^{c} / 10^{\mathrm{x}}\right)^{\mathrm{n}}\right)+\Phi\right)
$$

where $\mathrm{E}$ is the response; $\mathrm{E}_{\max }$ is the maximum response that the agonist can produce; $\mathrm{c}$ is the logarithm of the $\mathrm{EC}_{50}$, the concentration of agonist that produces halfmaximal response; $\mathrm{x}$ is the logarithm of the concentration of agonist; the exponential term, $\mathrm{n}$, is a curve fitting parameter that defines the slope of the concentrationresponse line, and $\Phi$ is the response observed in the absence of added agonist. Nonlinear regression analyses to determine the parameters $\mathrm{E}_{\max } \log \mathrm{EC}_{50}$ and $\mathrm{n}$ were done using GraphPad Prism (GraphPad Software, San Diego-CA, USA) with the constraint that $\Phi=$ zero.

\section{Lipid profile, glucose and insulin concentration}

After 12 weeks, animals were sacrificed after an overnight fasting. Blood samples were taken from descendent aorta under anesthesia with pentobarbital sodium $(30 \mathrm{mg} / \mathrm{kg}$, i.p.). Plasma and serum were immediately separated by centrifugation $(8,000 \mathrm{~g})$. Glucose levels and lipid profile were assessed by using specific commercial kits (colorimetric method, Laborlab, São Paulo, Brazil). Insulin concentration was determined by radioimmunoassay as 
described previously [19]. Homeostasis Model Assessment (HOMA), an index of insulin resistance was calculated according to a method previously described [20].

\section{Determination of plasma nitrite/nitrate $\left(\mathrm{NO}_{x}{ }^{-}\right)$levels}

In order to evaluate the NO production, the plasma levels of nitrite/nitrate $\left(\mathrm{NO}_{\mathrm{x}}{ }^{-}\right)$were measured. Briefly, immediately after arterial blood collecting, the samples were centrifuged $(8,000 \mathrm{~g})$ for $10 \mathrm{~min}$, and the resulting plasma supernatant was stored at $-80^{\circ} \mathrm{C}$. Plasma samples were ultrafiltered through microfilter cups (Microcon Centrifugal Filter Units, $10 \mathrm{kDa}$; Millipore, Bedford, MA, USA). The $\mathrm{NO}_{\mathrm{x}}{ }^{-}$concentration of the resulting filtrate solution was determined using a commercially available kit (Cayman Chemical, Ann Arbor, MI, USA) according to the manufacturer's instructions. This assay determines the total NO based on the enzymatic conversion of nitrate to nitrite by nitrate reductase. After the conversion, the spectrophotometric measurement of nitrite is accomplished by using the Griess Reaction. The resulting deep purple azo compound absorbs light at 540-550 nm.

\section{Western blotting assay for $\mathrm{Cu} / \mathrm{Zn}$ superoxide dismutase} In order to evaluate the contribution of $\mathrm{Cu} / \mathrm{Zn}$ superoxide dismutase (SOD-1) in endothelial cells in response to exercise training, aortic and mesenteric expression of SOD-1 was determined by Western blotting assays. Frozen segments of aorta and mesenteric arteries were homogenized and protein concentration was determined using Bradford method [21]. Samples containing $50 \mu \mathrm{g}$ protein were loaded into gels and eletrophoresed, and proteins were subsequently eletroblotted in polyvinylidene difluoride membranes. Primary antibody was mouse anti $\mathrm{Cu} / \mathrm{Zn}$ SOD (1:1500, SIGMA, St. Louis, MO, USA). Chemiluminescent signals (ECL plus Amersham, Piscataway, NJ, USA) were captured on X-ray film (Hyperfilm Amersham, Piscataway, NJ, USA), and scanning densitometry was used to quantify the immunoblot signals.

\section{Drugs and solutions}

Acetylcholine, sodium nitroprusside, and phenylephrine were purchased from SIGMA (St. Louis, MO, USA). All other reagents used were of analytical grade.

\section{Statistical analyses}

Data are presented as means \pm standard error mean (SEM) of $n$ experiments. Comparison of studied parameters and agonist responses was performed by analysis of variance (ANOVA two-way) to determine high caloric diet consumption and exercise training interference in results. Pearson correlation was used to determine association between triglycerides concentration and endothelium dependent relaxation evoked by acetylcholine. Statistical program SPSS 10.0 was used and the level of statistical significance employed was $\mathrm{p}<0.05$.

\section{Results}

Body weight at initial time of the study was similar in all groups. High caloric diet consumption provoked an increase in body weight gain in SDD group, approximately $13 \%$ as compared with SD group. Exercised animals (TR and TRD) showed a smaller weight gain, approximately $16 \%$, as compared with their sedentary groups (SD and SDD). The amount of food intake was also smaller in trained animals (TR and TRD groups) as compared with its matched-sedentary animals (SD and SDD groups). Data are summarized in Table 1 and illustrated in Figure 1.

High caloric diet consumption for 8 weeks provoked a marked increase in triglycerides concentration in SDD group, approximately $138 \%$, which was almost restored to the basal values by exercise training. Furthermore, exercise training per se reduced triglycerides levels, approximately $40 \%$ (Table 1 ). Glucose concentration was significantly greater in SDD group, about $24 \%$, as compared with SD group, and run training did not modify this parameter. Similarly, high caloric diet markedly increased insulin concentration in SDD group, approximately $194 \%$ as compared to SD group. Exercise training for 12

Table I: Effect of exercise training on body weight, triglycerides, serum glucose, insulin and nitrite/nitrate concentration from animals fed with standard chow or high caloric diet

\begin{tabular}{lcccc}
\hline & SD & TR & SDD & TRD \\
\hline Initial body weight $(\mathrm{g})$ & $306 \pm 7$ & $297 \pm 6$ & $306 \pm 8$ & $301 \pm 8$ \\
Final body weight $(\mathrm{g})$ & $478 \pm 9$ & $401 \pm 8^{\mathrm{a}}$ & $538 \pm 1 \mathrm{c}$ & $452 \pm 1 \mathrm{~b}^{\mathrm{b} d}$ \\
Triglycerides $(\mathrm{mg} / \mathrm{dl})$ & $91 \pm 1 \mathrm{I}$ & $55 \pm 8^{\mathrm{a}}$ & $216 \pm 25^{\mathrm{c}}$ & $89 \pm 9 \mathrm{~b}$ \\
Glucose $(\mathrm{mg} / \mathrm{dl})$ & $126 \pm 6$ & $140 \pm 8$ & $156 \pm 8^{\mathrm{c}}$ & $153 \pm 9$ \\
Insulin $(\mathrm{ng} / \mathrm{ml})$ & $0.87 \pm 0.10$ & $0.54 \pm 0,10^{\mathrm{a}}$ & $2.57 \pm 0.32^{\mathrm{c}}$ & $1.24 \pm 0.32^{\mathrm{b}}$ \\
HOMA IR & $0.61 \pm 0.11$ & $0.45 \pm 0.09^{\mathrm{a}}$ & $2.42 \pm 0.24^{\mathrm{c}}$ & $1.08 \pm 0.32^{\mathrm{b} d}$ \\
Nitrite/nitrate $(\mu \mathrm{M})$ & $27 \pm 4$ & $28 \pm 6$ & $27 \pm 3$ & $30 \pm 2$
\end{tabular}

Data are mean \pm S.E.M. for $n=8$ animals in each group. SD: sedentary, TR: trained, SDD: sedentary diet, TRD: trained diet. a trained vs sedentary; ${ }^{b}$ trained diet vs sedentary diet; ${ }^{c}$ sedentary diet vs sedentary; ${ }^{\mathrm{d}}$ trained diet $v$ s trained. 
A

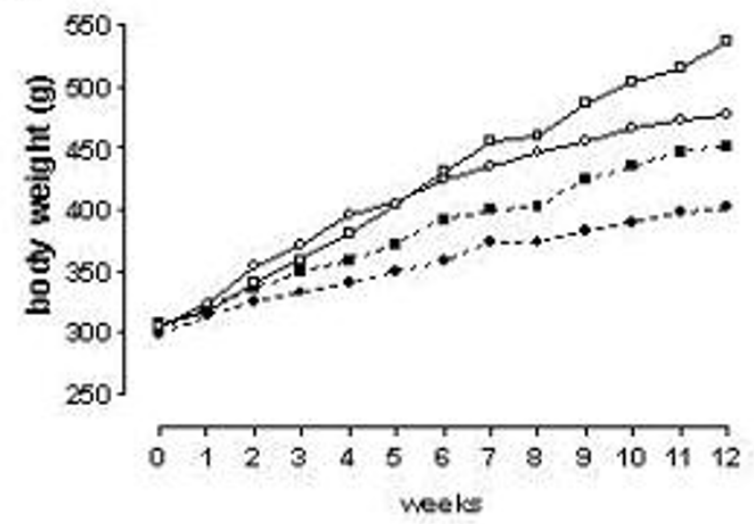

B

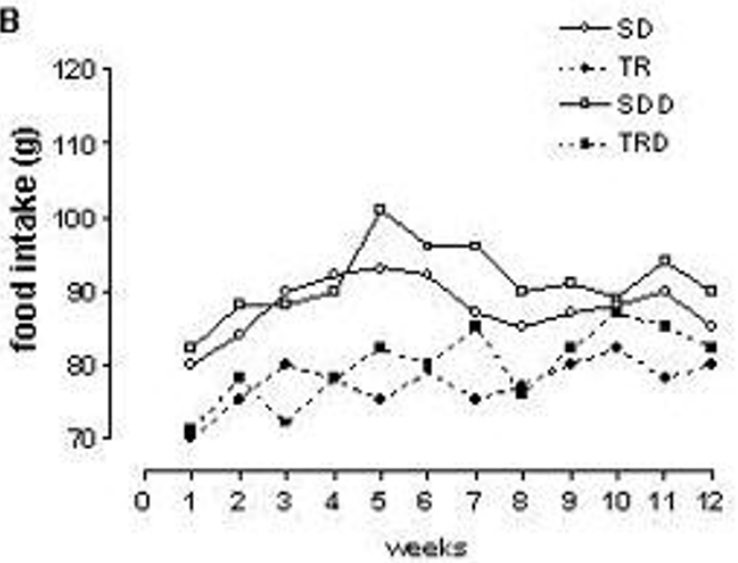

Figure I

Body weight gain (A) and mean food intake (B) during experimental protocol.

weeks attenuated the increase of insulin concentration, approximately $52 \%$ in TRD group as compared with SDD animals. Additionally, exercise training per se produced a decrease in insulin concentration (38\%) as compared to SD group (Table 1).

In order to verify the insulin resistance, HOMA index was calculated in all groups. High caloric diet produced an increase of HOMA index whereas exercise training alone or associated with high caloric diet consumption produced a significant reduction in this parameter indicating improvement in insulin sensitivity. To evaluate the production of NO metabolites in response to exercise training, the plasma $\mathrm{NO}_{\mathrm{x}}{ }^{-}$concentration was measured. Our findings showed that $\mathrm{NO}_{\mathrm{x}}{ }^{-}$levels were not modified in all groups (Table 1).

Endothelium-dependent relaxation responses were evaluated by construction of full concentration-response curves to acetylcholine (ACh) in aortic and mesenteric rings. In aortic rings, run training per se produced an increase of the maximal responses to ACh, compared with SD group. Similarly, an increase in the maximal responses to ACh in aortic ring from TRD group was observed. In mesenteric rings, the maximal responses to ACh was reduced in SDD animals while the run training for 12 weeks reversed the impairment of the relaxation responses produced by high caloric diet in TRD group (Figure 2). Similarly, run training alone (TR group) provoked an increase of the maximal responses for ACh (10\%). No changes were found in the potency values for this muscarinic agonist in all groups. Data are illustrated in Figure 2. A strong correlation between triglycerides concentration and impairment of relaxing response for ACh was found in both preparations (Figure 3).

Figure 4 illustrates the concentration-response curves to SNP in aortic and mesenteric rings. This NO donor produced concentration-dependent relaxing responses in both preparations in all groups. Neither maximal responses nor potency values were altered by exercise training (TR group) or high caloric diet consumption (SDD and TRD groups) in both preparations.

Data from Western blotting analysis in isolated aorta and mesenteric arteries from trained animals fed with standard chow or high caloric diet (TR and TRD groups) showed an increase in the expression of antioxidant enzyme SOD-1, approximately 30\%. In mesenteric artery, SOD-1 expression was significantly reduced in SDD animals, but not in aortic rings (Figure 5).

\section{Discussion}

The present study is the first to show that physical preconditioning at moderate intensity restores the impairment of relaxing response in mesenteric rings from high caloric diet-fed rats, which was positively associated with reduction in triglycerides concentration and up-regulation in SOD-1 expression.

Although a variety of experimental models of obesity exist, such as genetic, drugs and diet manipulations, dietary-induced obesity is the most relevant experimental model regarding to human obesity [22]. Our present findings show that run training was effective to reduce the body weight gain and the amount of food intake, indicat- 


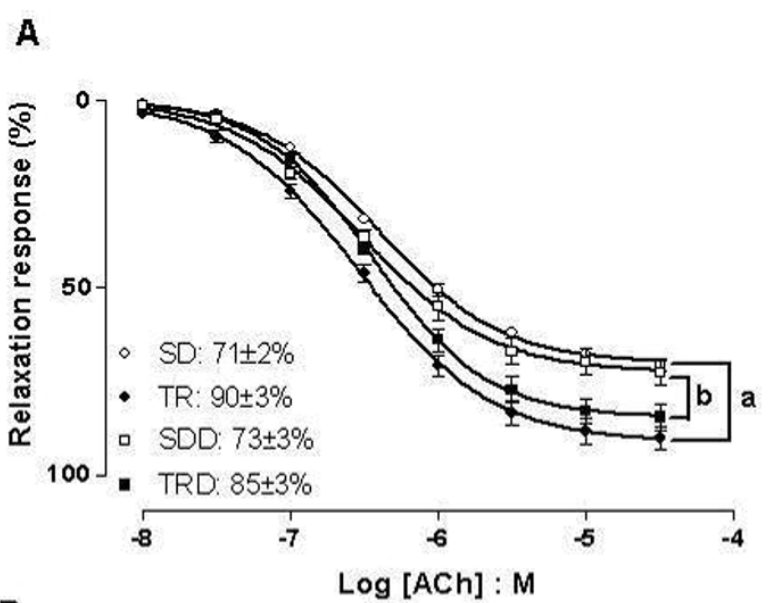

B

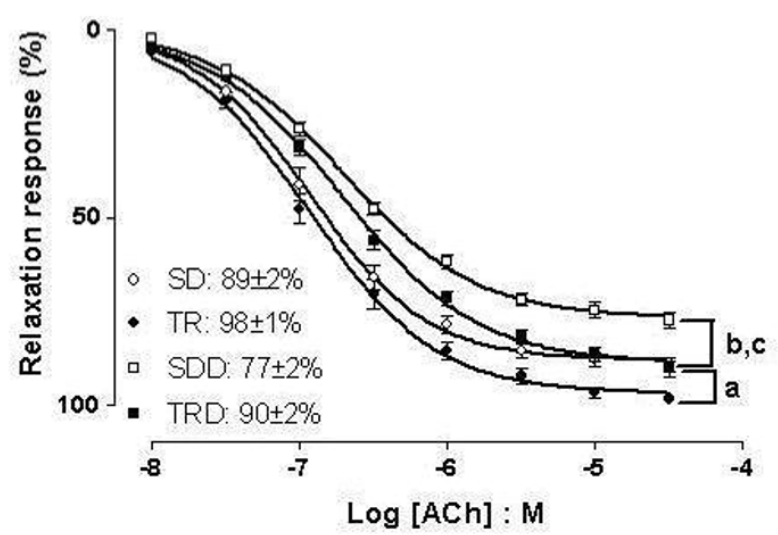

Figure 2

Concentration response curves to $\mathrm{ACh}$ in aortic (A) and mesenteric (B) rings. Data are means \pm SEM of $n=$ 5-6 in each group. SD: sedentary, TR: trained, SDD: sedentary diet, TRD: trained diet. a trained vs sedentary; ${ }^{b}$ trained diet vs sedentary diet; ${ }^{c}$ sedentary diet vs sedentary.

A

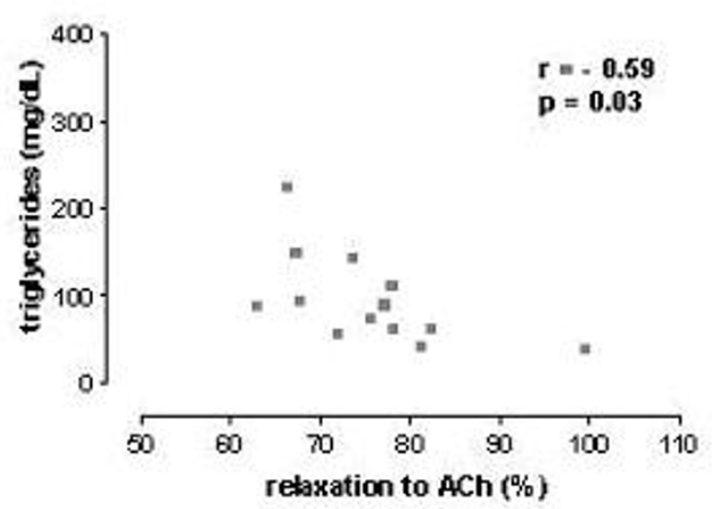

ing that aerobic physical exercise is an important approach in management of both parameters in this particular experimental obesity model.

Impairment of endothelium-dependent relaxation of blood vessels has been consistently demonstrated in a number of studies as a consequence of obesity $[6,7,23]$. A variety of factors have been proposed to explain the obesity-related endothelial dysfunction including alteration in the adipocyte-derived hormones resistin, adiponectin and leptin [24,25], high plasma triglycerides concentration and increase of oxidative stress $[6,7,23,26]$. In the present study, high caloric diet significantly produced an impairment of endothelium-dependent relaxation for ACh in mesenteric rings, confirming previous studies.

It is well documented that physical exercise promotes beneficial effects in lipid profile $[10,27,28]$. Particularly, plasma triglycerides concentration is reduced after exercise training by increasing lipoprotein lipase activity in plasma clearing triglycerides from circulation and replenishing it to the skeletal muscle stores to the process of excitation-contraction coupling (27). Our findings show that physical exercise was efficient to decrease triglycerides concentration after high caloric diet, which was positively correlated with the improvement of maximal relaxation responses to ACh in isolated mesenteric rings. These findings indicate that triglycerides concentration is an important marker for endothelial dysfunction.

High caloric diets are frequently associated with insulin resistance and consequently hyperinsulinemia [29,30]. This condition is related to high level of free fatty acids that increases cellular diacylglycerol leading to activation of different protein kinase $\mathrm{C}$ isoforms that phosphorylates

B

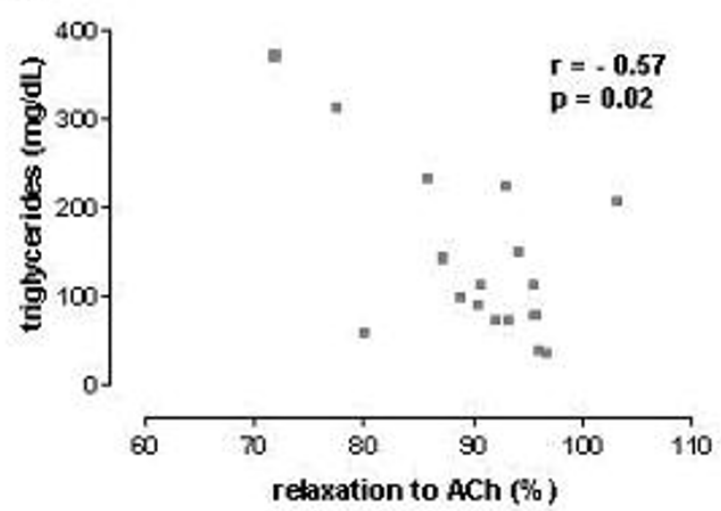

Figure 3

Correlation between triglycerides concentration and maximal relaxation responses to acetylcholine in aortic (A) and mesenteric rings (B). 


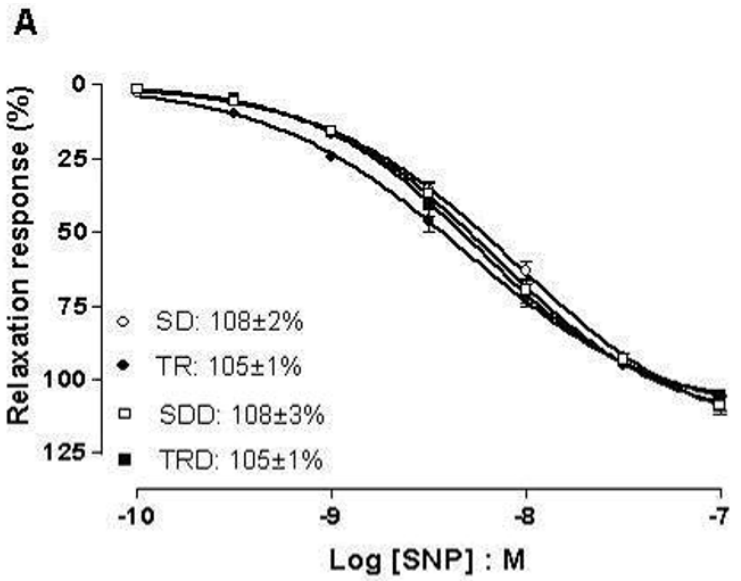

B

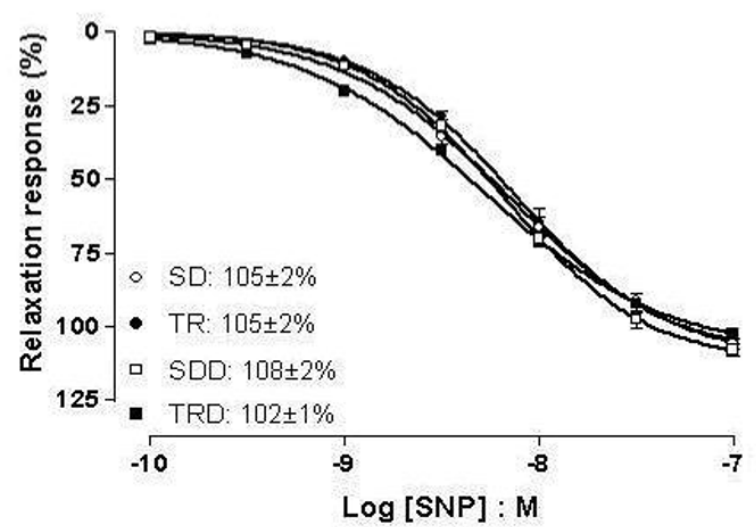

Figure 4

Concentration response curves to SNP in aortic (A) and mesenteric (B) rings. Data are means \pm SEM of $n=$ 5-6 in each group. SD: sedentary, TR: trained, SDD: sedentary diet, TRD: trained diet.

serine/threonine sites of insulin receptor (IR) and its substrates. The IR phosphorylation reduces its ability to activate PI3K leading to decrease of the glucose transporters GLUT-4 translocation to the cellular membrane resulting in impairment of glucose uptake [31]. In our study, a marked increase in insulin concentration was found in SDD group that was attenuated after exercise training for 12 weeks, showing clearly the beneficial effects of physical exercise in management of hyperinsulinemia. Similarly, high caloric diet consumption increased blood glucose level, but exercise training failed to restore it to the baseline. The reasons for that could be the magnitude of the alterations in glycemia (approximately of 24\%) as compared with insulinemia (approximately 194\%) in SDD group. Previous studies have also showed that only a slight increase (or no change) in glucose concentration is seen in dietary-obese rats [30-33].
Either in human or laboratory animals, the cardiovascular benefits of exercise training have been associated with a variety of cellular and molecular alterations including upregulation of endothelial NO synthase (eNOS), increase in expression and/or activity of antioxidant enzymes, as well as decrease in prooxidant enzyme systems [34,35]. The antioxidant defense systems consist of enzymes such as SOD, catalase and glutathione peroxidase, and nonenzymes including vitamins and flavonoids [36]. The antioxidant enzymes are scavengers of reactive oxygen species (ROS) causing an increase of NO bioavailability to the vascular smooth muscle and enhancement of endothelium-dependent vasodilatation [37-39].

Considering the variety of the receptors and signaling pathways present in the vascular smooth muscle and endothelial cells to trigger the relaxing response, the evaluation of exercise training in the responsiveness of vascular blood vessel is a complex issue. Additionally, multiple interactions exist between the stimulus of an agonist and the vascular response including the affinity of receptoragonist, metabolism of drugs, existence of antioxidant and prooxidant enzymes in the cell, and the contribution of several protein regulators in the phosphorylation process [35]. At least three isoforms of SOD exist in mammalian tissues, namely $\mathrm{Cu} / \mathrm{Zn}$ SOD (SOD1), MnSOD (SOD2) and extracellular SOD (EcSOD or SOD3) that are located in cytosol, mitochondria and vascular smooth muscle, respectively $[40,41]$. Thus, to assess the underlying mechanisms by which exercise training ameliorates the vascular responsiveness in this particular model we have chosen to analyze SOD-1 expression in both arteries and plasma $\mathrm{NO}_{\mathrm{x}}{ }^{-}$concentration for two reasons. First, SOD-1 represents a major cellular defense against superoxide anion and peroxynitrite formation in endothelial cells. Second, the primary focus of our study was to evaluate the effect of exercise training on endothelium function.

Interestingly, in both aortic and mesenteric rings, an increase in SOD-1 expression in trained groups was found. This up-regulation of SOD was accompanied by an increased in relaxing response for endothelium-dependent agonist. Therefore, our findings clearly show a strong relationship between the improvement in relaxing response seen in trained animals and up-regulation of SOD-1 expression. This is consistent with previous reports in porcine aorta showing that chronic exercise training increases SOD-1 expression associated with improvement in relaxing response $[42,43]$.

In the present study, either high caloric diet or exercise training did not modify the NO production, as estimated by plasma $\mathrm{NO}_{\mathrm{x}}{ }^{-}$quantification. Previous studies also failed to show a direct correlation between increased NO 

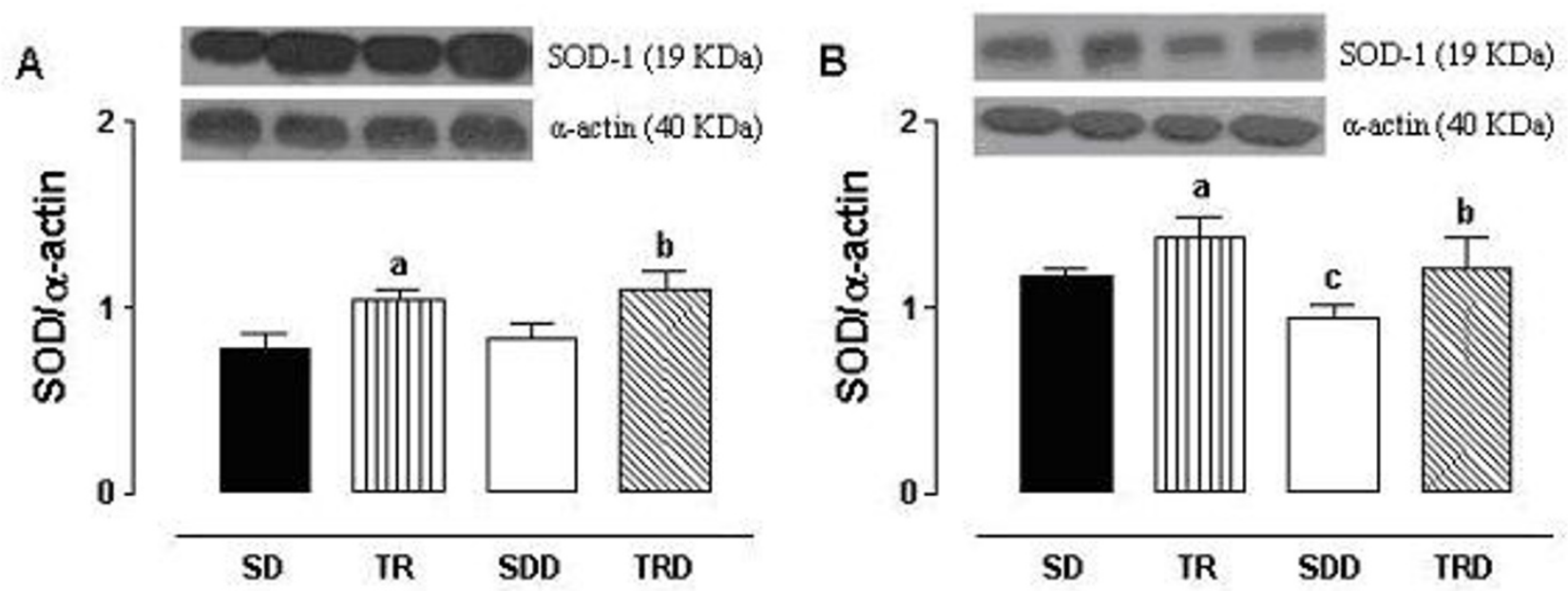

Figure 5

Effects of exercise training in the SOD-I expression from isolated rat aorta (panel A) and mesenteric (panel B) arteries. Representative Western blot (top) and quantitative analysis (bottom) for SOD-I protein expression. Data are means \pm SEM of $n=7-8$ per group. SD: sedentary, TR: trained, SDD: sedentary diet, TRD: trained diet. a trained vs sedentary; $b$ trained diet vs sedentary diet; ${ }^{\mathrm{c}}$ sedentary diet vs sedentary.

production and improvement of endothelium-dependent dilation after exercise training [8,42-47], which may be attributed to differences in duration, intensity, and frequency of the training program employed in each study. In fact, to evaluate the effect of exercise training on molecular mechanisms, it is important to consider the total volume of an exercise training program, which is based upon the frequency, intensity, and duration. Accordingly, previous study found that four weeks of exercise training produced an increase of NO production that was positively associated with improvement of relaxing response for endothelium-dependent agonist [48].

In conclusion, in our study, the improvement in endothelial function found in both arteries from trained high caloric-fed rats was directly related to an increase in NO bioavailability to the smooth muscle due to SOD-1 up regulation.

\section{Authors' contributions}

CdM conceived of the project, collected and analyzed the data and wrote the manuscript; APCD and LVR participated in the Western blotting analyses; EA provided laboratories conditions and participated in the project conception; AZ participated in the project conception, the study design, data analysis and writing the manuscript.

\section{Additional material}

\section{Additional file 1}

Click here for file

[http://www.biomedcentral.com/content/supplementary/14726793-8-12-S1.jpeg]

\section{Acknowledgements}

We are grateful for financial support from Coordenação de Aperfeiçoamento de Pessoal de Nível Superior (CAPES) and Fundação de Amparo à Pesquisa do Estado de São Paulo (FAPESP). L.V.R. is a research fellow from CNPq.

\section{References}

I. Hall JE: Pathophysiology of obesity hypertension. Curr Hypertens Rep 2000, 2(2): 139-147.

2. Barter PJ, Rye KA: High density lipoproteins and coronary heart disease. Atherosclerosis 1996, I 2 I(I): I-I2.

3. Diaz MN, Frei B, Vita JA, Keaney JF Jr: Antioxidants and atherosclerotic heart disease. N EnglJ Med 1997, 337(6):408-416.

4. Rush JW, Denniss SG, Graham DA: Vascular nitric oxide and oxidative stress: determinants of endothelial adaptations to cardiovascular disease and to physical activity. Can J Appl Physiol 2005, 30(4):442-474.

5. Luz PL, Favarato D, Laurindo FRM: Oxidative theory of atherosclerosis: why did large trials not show benefits? Int J Atheroscler 2006, I(2): 124-136.

6. Naderali EK, Brown MJ, Pickavance LC, Wilding JPH, Doyle PJ, Williams G: Dietary obesity in the rat induces endothelial dys- 
function without cause insulin resistance: a possible role for triacylglycerols. Clin Sci 200I, I0I(5):499-506.

7. Naderali EK, Fatani S, Williams G: Chronic withdrawal of a highpalatable obesity-inducing diet completely reverses metabolic and vascular abnormalities associated with dietaryobesity in the rat. Atherosclerosis 2004, I72(I):63-69.

8. Woodman CR, Thompson MA, Turk JR, Laughlin MH: Endurance exercise training improves endothelium-dependent relaxation in brachial arteries from hypercholesterolemic male pigs. J Appl Physiol 2005, 99(4): |4|2-I42I.

9. Turk JR, Henderson KK, Vanvickle GD, Watkins J, Laughlin MH: Arterial endothelial function in a porcine model of early stage atherosclerotic vascular disease. Int J Exp Pathol 2005, 86(5):335-345.

10. Halverstadt A, Phares DA, Wilund KR, Goldberg AP, Hagberg JM Endurance exercise training raises high-density lipoprotein cholesterol and lowers small low-density lipoprotein and very low-density lipoprotein independent of body fat phenotypes in older men and women. Metabolism 2007, 56(4):444-450.

II. Delp MD, McAllister RM, Laughlin MH: Exercise training alters endothelium-dependent vasoreactivity of rat abdomina aorta. J Appl Physiol I 993, 75(3): | 354-| 363 .

12. Sessa WC, Pritchard K, Seyedi N, Wang J, Hintze TH: Chronic exercise in dogs increases coronary vascular nitric oxide production and endothelial cell nitric oxide synthase gene expression. Circ Res 1994, 74(2):349-353.

13. Shen W, Lundborg M, Wang J, Stewart JM, Xu X, Ochoa M, Hintze $\mathrm{TH}$ : Role of EDRF in the regulation of regional blood flow and vascular resistance at rest and during exercise in conscious dogs. J Appl Physiol 1994, 77(1): 165-172.

14. Woodman CR, Muller JM, Laughlin MH, Price EM: Induction of nitric oxide synthase mRNA in coronary resistance arteries isolated from exercise-trained pigs. Am J Physiol 1997, 273(6): $\mathrm{H} 2575-2579$.

15. Kingwell BA: Nitric oxide-mediated metabolic regulation during exercise: effects of training in health and cardiovascular disease. FASEB J 2000, I 4(I 2): 1685-1696.

16. Maeda S, Miyauch T, Kakiyama T, Sugawara J, lemitsu M, IrukayamaTomobe Y, Murakami H, Kumagai Y, Kuno S, Matsuda M: Effects of exercise training of 8 weeks and detraininig on plasma levels of endothelium-derived factors, endothelin- 1 and nitric oxide, in healthy young humans. Life Sci 200I, 69(9): 1005-1016.

17. Maiorana A, O'Driscoll G, Taylor R, Green D: Exercise and the nitric oxide vasodilator system. Sports Med 2003, 33(14): $1013-1035$.

18. Dobrian AD, Davies MJ, Prewitt RL, Lauterio TJ: Development of hypertension in a rat model of diet-induced obesity. Hypertension 2000, 35(4): 1009-1015.

19. Herbert V, Lau KS, Gottlieb CW, Bleicher S): Coated charcoal immunoassay of insulin. I Clin Endocrinol Metab 1965 , 25(10): I375-1384.

20. Matthews DR, Hosker JP, Rudenski AS, Naylor BA, Treacher DF, Turner RC: Homeostasis model assessment: insulin resistance and beta-cell function from fasting plasma glucose and insulin concentrations in man. Diabetologia 1985, 28(7):4|2-4| 9 .

21. Bradford MM: A rapid and sensitive method for the quantitation of microgram quantities of protein utilizing the principle of protein-dye binding. Anal Biochem 1976, 7(72):248-254.

22. Tschöp M, Heiman ML: Rodent obesity models: an overview. Exp Clin Endocrinol \& Diabetes 200I, 109(6):307-319.

23. Naderali EK, Williams G: Prolonged endothelial-dependent and -independent arterial dysfunction induced in the rat by short-term feeding with a high-fat, high-sucrose diet. Atherosclerosis 2003, 166(2):253-259.

24. Kougias $P$, Chai $H$, Lin PH, Yao Q, Lumsden AB, Chen C: Effects of adipocyte-derived cytokines on endothelial functions: implication ofvascular disease. J Surg Res 2005, I 26(I): I2I-129.

25. Galili O, Versari D, Sattler KJ, Olson ML, Mannheim D, McConnell JP, Chade AR, Lerman LO, Lerman A: Early experimental obesity is associated with coronary endothelial dysfunction and oxidative stress. Am J Physiol Heart Circ Physiol 2007, 292(2):H904-9II.

26. Fortuño A, San José G, Moreno MU, Díez J, Zalba G: Oxidative stress and vascular remodeling. Exp Physiol 2005, 90(4):457-462.

27. Oscai LB, Essig DA, Palmer WK: Lipase regulation of muscle triglyceride hydrolysis. J Appl Physiol 1990, 69(5):I57I-I577.
28. Hennig B, Toborek M, McClain C): High-energy diets, fatty acids and endothelial cell function: implications for atherosclerosis. J Am Coll Nutr 200I, 20(2 suppl):97-105.

29. Barnard RJ, Roberts CK, Varon SM, Berger J]: Diet-induced insulin resistance precedes other aspects of the metabolic syndrome. J Appl Physiol 1998, 84(4):|3|I-|3|5.

30. Straczkowski M, Kowalska I, Dzienis-Straczkowska S, Kinalski M, Górski J, Kinalska I: The effect of exercise training on glucose tolerance and skeletal muscle triacylglycerol content in rats fed with a high-fat diet. Diabetes Metab 200I, 27(I):19-23.

31. Krebs M, Roden M: Molecular mechanisms of lipid-induced insulin resistance in muscle, liver and vasculature. Diabetes Obes Metab 2005, 7(6):621-632.

32. López IP, Marti A, Milagro FI, Zulet Md Mde L, Moreno-Aliaga MJ, Martinez JA, De Miguel C: DNA microarray analysis of genes differentially expressed in diet-induced (cafeteria) obese rats. Obes Res 2003, I I (2): I88-194.

33. Estadella D, Oyama LM, Dâmaso AR, Ribeiro EB, Oller Do Nascimento CM: Effect of palatable hyperlipidic diet on lipid metabolism of sedentary and exercised rats. Nutrition 2004, 20(2):218-224

34. Higashi Y, Yoshizumi M: Exercise and endothelial function: role of endothelium-derived nitric oxide and oxidative stress in healthy subjects and hypertensive patients. Pharmacol Ther 2004, I02(I):87-96.

35. Zanesco A, Antunes E: Effects of exercise training on the cardiovascular system: Pharmacological approaches. Pharmacol Ther 2007, II 4(3):307-3I7.

36. Droge W: Free radicals in the physiological control of cell function. Physiol Rev 2002, 82(I):47-95.

37. Dimmeler S, Fleming I, Fisslthalter B, Hermann C, Busse R, Zeiher AM: Activation of nitric oxide synthase in endothelial cells by Akt-dependent phosphorylation. Nature 1999, 399(6736):60I-605.

38. Davis KL, Martin E, Turko IV, Murad F: Novel effects of nitric oxide. Annu Rev Pharmacol Toxicol 200I, 41:203-236.

39. Davis ME, Cai H, McCann L, Fukai T, Harrison DG: Role of c-Src in regulation of endothelial nitric oxide synthase expression during exercise training. Am J Physiol Heart Circ Physiol 2003, 284(4):HI449-I453.

40. Inoue N, Ramasamy S, Fukai T, Nerem RM, Harrison DG: Shear stress modulates expression of $\mathrm{Cu} / \mathrm{Zn}$ superoxide dismutase in human aortic endothelial cells. Circ Res 1996, 79(I):32-37.

4I. Fukai T, Folz RJ, Landmesser U, Harrison DG: Extracellular superoxide dismutase and cardiovascular disease. Cardiovasc Res 2002, 55(2):239-249.

42. Rush JW, Turk JR, Laughlin MH: Exercise training regulates SOD-I and oxidative stress in porcine aortic endothelium. Am J Physiol Heart Circ Physiol 2003, 284(4):HI 378-I387.

43. Thompson MA, Henderson KK, Woodman CR, Turk JR, Rush JW, Price $\mathrm{E}$, Laughlin $\mathrm{MH}$ : Exercise preserves endothelium-dependent relaxation in coronary arteries of hypercholesterolemic male pigs. J Appl Physiol 2004, 96(3): | | |4-I I26.

44. Oltman CL, Parker JL, Adams HR, Laughlin MH: Effects of exercise training on vasomotor reactivity of porcine coronary arteries. Am J Physiol 1992, 263(2 Pt 2): $\mathrm{H} 372-382$

45. McAllister RM, Kimani JK, Webster JL, Parker JL, Laughlin MH: Effects of exercise training on responses of peripheral and visceral arteries in swine. J Appl Physiol 1996, 80(I):216-225.

46. Jasperse JL, Laughlin MH: Vasomotor responses of soleus feed arteries from sedentary and exercise-trained rats. J Appl Physiol 1999, 86(2):44I-449.

47. Henderson KK, Turk JR, Rush JW, Laughlin MH: Endothelial function in coronary arterioles from pigs with early-stage coronary disease induced by high-fat, high-cholesterol diet: effect of exercise. J Appl Physiol 2004, 97(3): I I59-I I68.

48. De Moraes C, Camargo EA Antunes E, De Nucci G, Zanesco A Reactivity of mesenteric and aortic rings from trained rats feed with high caloric diet. Comp Biochem Physiol A 2007, I47(3):788-792. 